\section{Tratado médico-filosófico sobre a alienação mental ou a mania}

Pinel P. Tradução: Joice Armani Galli. Porto Alegre: Editora da UFRGS; 2007. 272p. ISBN 978-85-7025-948-6

Inicialmente, é preciso parabenizar os editores e a equipe envolvida na tradução e revisão deste clássico que é considerado um marco no nascimento da moderna psiquiatria. 0 precário conhecimento da história da medicina entre os clínicos e pesquisadores acarreta graves limitações na formação humanística e na capacidade de avaliação crítica das pesquisas e práticas em saúde. O pouco contato que temos com a história de nossa profissão é habitualmente feito por meio de textos elaborados por médicos sem adequada formação em História. O resultado é que, geralmente, temos acesso a uma visão simplista na qual alguns iluminados libertaram a humanidade da ignorância e da superstição. Habitualmente, vemos as práticas antigas como equívocos tolos e que atualmente vivenciamos o apogeu da Medicina, guiada pela real ciência e possuidora da verdade. É comum perceber um tom triunfalista nesses escritos de historiadores não profissionais ou mesmo em muitos editoriais das principais revistas médicas do mundo.

Um bom antídoto contra tal atitude é a leitura direta dos textos originais que fizeram a história de nossa profissão. Nesse exercício, perceberemos, muitas vezes, o mesmo tom triunfalista em escritos de mais de cem anos, quando, por exemplo, na psiquiatria, não estava disponível nenhum dos tratamentos contemporaneamente reconhecidos como eficazes. Tal leitura pode nos causar um desagradável mas salutar sentimento de déjà vu. Como ouvi certa vez num congresso, "é preciso que nos lembremos que estamos sempre no meio na história, nunca no fim dela". Esta percepção nos ajuda a manter uma humildade intelectual que nos imuniza contra muitos equívocos.

Por tudo isso, o trabalho de lançamento da versão em português do Tratado Médico-Filosófico de Pinel merece ser vigorosamente louvado. Essa obra, publicada pela primeira vez em Paris, em 1800 , relata as pesquisas de Pinel durante quase dois anos como médico do hospício de Bicêtre, pouco depois da revolução francesa. Naturalmente, uma obra de tamanha importância comporta análises sob diferentes prismas. Nesta resenha, me concentrarei em alguns aspectos que me chamaram a atenção enquanto clínico e pesquisador em psiquiatria do início do século XXI lendo um trabalho escrito há mais de dois séculos. Assim, não entrarei em análises históricas, mas me deterei em algumas possíveis implicações para nossa prática atual como clínicos e pesquisadores em psiquiatria.

A obra conta com uma apresentação escrita por Ana Oda e Paulo Dalgalarrondo, que abordam aspectos muito interessantes da história da psiquiatria na Europa e América, bem como o impacto de Pinel no Brasil. Nela aprendemos, inclusive, que um dos filhos de Pinel imigrou para o Brasil, havendo até hoje descendentes dele em nosso país. Esse breve texto ajuda a preencher a enorme lacuna de textos de qualidade em história da psiquiatria no Brasil.

Um dos aspectos que chama a atenção no trabalho de Pinel diz respeito à sua crítica à postura dogmática, cômoda e vaidosa de muitos médicos, o que, muitas vezes, impediria o real desenvolvimento da medicina e acarretaria muitos malefícios

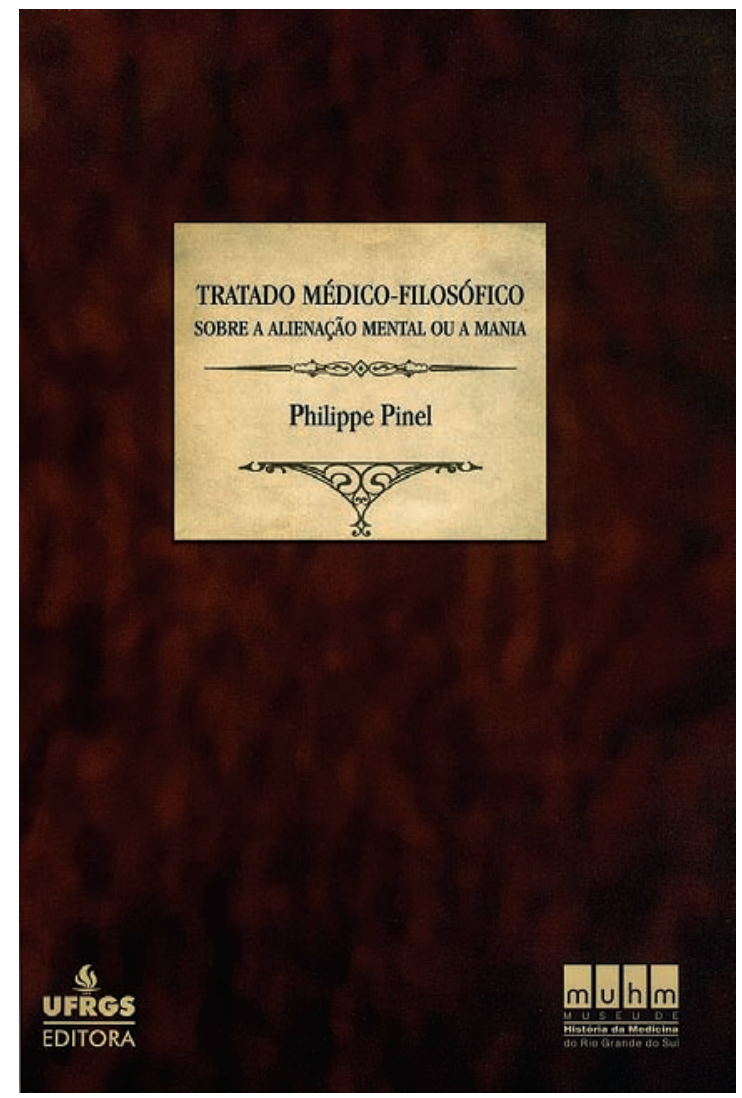

aos pacientes. Pinel comenta o quanto a vaidade, a "arte de se fazer valer" (p. 48), faz com que proliferem sistemas vazios de classificação, explicação e tratamento das alienações mentais. Comenta sobre a falta de pesquisas rigorosas e o excessivo número de compilações que, com base no prestígio de seus autores e no uso de termos rebuscados, impressionam a muitos, mas que na realidade apenas camuflam nossa ignorância. Interroga: "deverse-ia confundir os resultados verdadeiros da observação com os desvios de uma doutrina apegada aos preconceitos, ao espírito de hipótese, ao reino do pedantismo e da ignorância, à autoridade dos nomes célebres?" (p. 221-2). Nesse contexto, "nada parecia mais fácil, segundo suas belas e doutas explicações, que curar a alienação. Sua causa era sem dúvida (...) um humor que cumpria preparar por medicamentos preliminares para lhe dar caça e expulsá-lo (...). A natureza inteira parecia contribuir com essas sábias operações, fazendo surgir medicamentos numerosos" (p. 50). Isto certamente nos soa bastante familiar em relação ao entusiasmo excessivo no foco exclusivo nos fatores neurobiológicos, que tem resultado em avanços questionáveis na vida dos portadores de transtornos mentais. ${ }^{1,2}$

Pinel comenta sobre o entusiasmo irrefletido e o uso excessivo de medicações e procedimentos como duchas e sangrias que, quando não danosos, eram inócuos. Pinel lembra que "a habilidade do médico está longe de consistir no uso exclusivo de medicamentos" (p. 73). Pondera que muitos "autores não tiveram outro objetivo a não ser dar validade a alguns remédios, como se o tratamento de toda doença, sem conhecimento exato de seus sintomas, e de sua marcha, não fosse tão perigoso quanto ilusório" (p. 76). Reflete sobre as fragilidades dos relatos de sucessos de novas terapias e enfatiza a necessidade de ponderação e critério no emprego 
de intervenções novas ou antigas. Algo semelhante parece ter acontecido recentemente com o uso dos novos antipsicóticos, que por mais de uma década pareciam ser muito eficazes, muito superiores aos típicos. Tais idéias têm sido gravemente questionadas por estudos independentes recentes, mostrando sérias limitações em termos de efetividade e de riscos não esperados. ${ }^{3-5}$ Como outro exemplo recente na medicina, que custou milhares de vidas, podese citar o uso do Vioxx ${ }^{6}$ (rofecoxib).

Do ponto de vista da atenção direta aos pacientes, chama atenção a postura de humildade de Pinel na disposição em aprender ao máximo com Pussin, "vigilante do hospício de alienados" ( $p$. 63). Pussin era o indivíduo responsável pelo cuidado direto aos alienados do Bicêtre, uma espécie de precursor da enfermagem psiquiátrica. Embora não tivesse formação acadêmica, tinha uma grande experiência no observar e lidar com pacientes psiquiátricos internados. "Que intolerância! Quanto de desprezo insultante não se destinou a homens (...) que, estranhos aos princípios da medicina e guiados somente por um julgamento sensato ou por alguma tradição obscura, dedicaram-se ao tratamento dos alienados, operando a cura de um grande número deles" (p. 62-3). Frente à sabedoria de Pussin, Pinel afirma: "o meu tom dogmático de doutor foi desde então abandonado" (p. 64). Percebe-se, ao longo da obra, o quanto o tratamento moral proposto por Pinel é basicamente a sistematização da abordagem desenvolvida e aplicada por Pussin e outros com funções e virtudes semelhantes em hospícios pela Europa.

$\mathrm{Na}$ leitura do "Tratado", aprendemos que o famoso "gesto de Pinel", retirando as correntes dos alienados, provavelmente nunca ocorreu, mas simboliza sua ênfase na humanização do atendimento. Há uma marcante valorização dos eventos vitais estressantes como desencadeantes de alienação, assim levando à necessidade de abordar os pacientes do ponto vista psicológico e comportamental (o que ele chamava de tratamento moral). A relação estabelecida entre o paciente e as pessoas que the oferecem cuidado é destacada como potente recurso terapêutico. Pinel condena veementemente qualquer tipo de violência contra os doentes. Há uma grande ênfase no esforço de trazer os pacientes novamente ao convívio social bem como no combate a preconceitos relativos às doenças mentais e seus portadores. Para isso, ele propõe a criação de asilos para alienados com qualidade e recursos para atingir este fim. Tais instituições deveriam ser amplas, arejadas, com áreas verdes e oferecerem possibilidade de exercícios físicos. Entre as várias propostas de organização dos "hospícios de alienados", destaca a importância da separação dos doentes por grupos de patologias ou de estado evolutivo do quadro, a necessidade de cuidados na preparação da alimentação dos alienados e a promoção de atividades laborativas de caráter terapêutico, específicas para cada paciente. Enfatiza a necessidade de, o que chamaríamos hoje, uma adequada referência e contra-referência de pacientes entre os vários hospitais e médicos de uma região para que se possa dar adequada continuidade ao tratamento.

Enfim, este livro é uma preciosidade que oferece farto material para estudo e reflexões para áreas muito diversas. Embora nesta resenha tenhamos enfatizado uns poucos aspectos, no "Tratado", encontra-se também elementos para interessados em tópicos como nosologia, nosografia, história da medicina e das ciências, farmacologia, tratamentos psicossociais, desencadeantes dos transtornos mentais, psicopatologia, psicossomática, entre outros. Uma limitação desta versão é o fato de que as referências internas que Pinel faz dentro da própria obra indicam números de página que não correspondem à da versão em português que temos (provavelmente se referem à paginação do original em francês). Seria também de grande valia se ao longo da obra houvesse notas da tradutora ou das revisoras esclarecendo sobre o contexto ou o significado de certas expressões, acontecimentos ou mesmo unidades de medida usadas ao longo da obra.

A leitura do "Tratado" oferece uma oportunidade valiosa para termos acesso em primeira mão a uma importante base da moderna psiquiatria, mas que mesmo assim nos oferece um olhar e uma abordagem dos transtornos mentais bastante diferentes dos que temos atualmente. Ou seja, é uma obra que nos proporciona condições de nos colocarmos em perspectiva no contexto da história da psiquiatria, nos permite lembrar que estamos sempre "no meio da história", nunca em seu fim. Esta é uma experiência importante, pois, de acordo com Pinel, como o médico "poderia seriamente analisar os inúmeros fatos que passam sob seus olhos, se ele se treinar servilmente em rotas já construídas e, igualmente, se ele for desprovido de espírito filosófico e do desejo ardente de instruir-se?" (p. 99).

Alexander Moreira-Almeida

Faculdade de Medicina, Universidade Federal de Juiz de Fora (UFJF), Juiz de Fora (MG), Brasil

\section{Referências}

1. Kingdon D, Young AH. Research into putative biological mechanisms of mental disorders has been of no value to clinical psychiatry. $\mathrm{Br} \mathrm{J}$ Psychiatry. 2007;191:285-90.

2. Moncrieff J. Psychiatric drug promotion and the politics of neoliberalism. Br J Psychiatry. 2006;188:301-2

3. Adams CE, Tharyan P, Coutinho ES, Stroup TS. The schizophrenia drug-treatment paradox: pharmacological treatment based on best possible evidence may be hardest to practice in high-income countries. Br J Psychiatry. 2006;189:391-2.

4. Jones PB, Barnes TR, Davies L, Dunn G, Lloyd H, Hayhurst KP, Murray RM, Markwick A, Lewis SW. Randomized controlled trial of the effect on Quality of Life of second- vs first-generation antipsychotic drugs in schizophrenia: Cost Utility of the Latest Antipsychotic Drugs in Schizophrenia Study (CUtLASS 1). Arch Gen Psychiatry. 2006;63(10): 1079-87.

5. Swartz MS, Perkins DO, Stroup TS, Davis SM, Capuano G, Rosenheck RA, Reimherr F, McGee MF, Keefe RS, McEvoy JP, Hsiao JK, Lieberman JA; CATIE Investigators. Effects of antipsychotic medications on psychosocial functioning in patients with chronic schizophrenia: findings from the NIMH CATIE study. Am J Psychiatry. 2007;164(3):428-36.

6. Horton R. Vioxx, the implosion of Merck, and aftershocks at the FDA. Lancet. 2004;364(9450):1995-6. 